\title{
Thermal, dielectric and catalytic behavior of palladium doped PVC films
}

\author{
Ganesh Shimoga ${ }^{1}$, Eun-Jae Shin ${ }^{1}$ and Sang-Youn Kim*
}

\begin{abstract}
${ }^{1}$ Interaction Laboratory of Advanced Technology Research Center, Korea University of Technology and Education, Byeongcheon-myeon, Cheonan City, South Korea

*sykim@koreatech.ac.kr
\end{abstract}

\begin{abstract}
The present paper discusses the aspects of synthesizing palladium $(\mathrm{Pd})$ doped $\left(\mathrm{Pd}^{+2}\right.$ and $\left.\mathrm{Pd}^{0}\right)$ poly $($ vinyl chloride $)(\mathrm{PVC})$ using simple solution cast technique. The Pd loading to PVC was altered from $2.5 \%$ to $10.0 \%$ and the material properties were studied using UV-Visible spectroscopy (UV-Vis), X-ray diffraction (XRD), Energy-dispersive X-ray spectroscopy (EDX) and Field Emission Scanning Electron Microscopy (FE-SEM). Thermal behavior of all the samples were studied using thermogravimetric analysis (TGA) and Broido's method was employed to analyse the kinetic parameters involved in different degradation steps. All the composite films were sandwitched between disk shape gold electrodes; electrical contacts were established to study the dielectric properties. The influence of Pd loading on the dielectric properties of PVC were examined. Finally, the catalytic properties of $\mathrm{Pd}^{0}$ composites were studied using standard model reduction reaction of 4-nitrophenol (4-NP) to 4-aminophenol (4-AP) in the presence of aqueous sodium borohydride and reported.
\end{abstract}

Keywords: dielectric, heterogeneous catalysis, palladium nanocomposites, poly(vinyl chloride), thermal analysis.

How to cite: Shimoga, G., Shin, E.-J., \& Kim, S.-Y. (2019). Thermal, dielectric and catalytic behavior of palladium doped PVC films. Polímeros: Ciência e Tecnologia, 29(2), e2019028. https://doi.org/10.1590/0104-1428.08718

\section{Introduction}

Efforts to develop composite materials in order to achieve exceptional characteristics different from the individual components have been in practice from decades by scientific community ${ }^{[1,2]}$. Polymer metal composites/nanocomposites have been spread their interest as catalysts in modern organic synthesis ${ }^{[3]}$, they have been widely used in aerospace and automobile industry, their properties are still being researched by tuning in electronic, sensors and catalytic applications ${ }^{[4-6]}$. Recent developments in solid ionic conductors, polymer electrolytes and intercalation materials have drawn keen interest from the researchers working in the field of plastic crystal ionic batteries, solid state galvanic cells and interfacial responsive sensory/electrical equipments ${ }^{[7-9]}$. In addition, the involvement of interfaces with metal composites play an important role in the regulation of composite properties ${ }^{[10]}$. Most of the thermoplastic polymers have widely been used in various fields from sensors to electrical equipment design due to their lightweight, ease of fabrication, exceptional processability, durability, and relatively low cost. Incorporation of various metallic oxides with thermoplastic polymers as polymer matrix have drawn profound applications in the removal of organic pollutants from water ${ }^{[11]}$ and some of the metal doped polymers are used as matrix materials for ferroelectric composites ${ }^{[12]}$.

Poly(vinyl chloride) (PVC) is one of the most commertially used thermosoftening plastic that have wide range of applications as fire retardants, corrosion resistance and electrical insulators. The miscibility and compatability of PVC with wide variety of organic/inorganic materials have been observed in differing mechanical and electrical properties from rigid to flexible compounds. Recently, the applications of reinforced PVC composites are preceded to new directions in the field of polymer science and technology ${ }^{[13]}$. Dieletric performances of PVC incorporated with ground tire rubber (GTR), calcium copper titanate, zinc additives, piezoelectric lead zirconatetitanate, silica nanocomposites, graphite, and mica were studied extensively for its optoelectrical applications ${ }^{[14-27]}$.

Due to remarkable catalytic activity of palladium nanoparticles (PdNPs), various bimetallic combinations of PdNPs with gold, nickel and other transitional metals, and also with supramolecules have paid much attention in the reduction of nitrophenol reduction reactions ${ }^{[28-30]}$. To best of our knowledge, no systematic practical research has been reported so far on the Pd doped PVC films for heterogeneous catalytic applications. In this present work, we made a successful attempt to fabricate Pd doped PVC films and subsequent reduction of the films by ecofriendly trisodium citrate dihydrate solution. The doping of $\mathrm{Pd}$ in PVC matrix was varied from 2.5 to $10.0 \%$ (Stochiometric weight \%) and thermal degradation of Pd-PVC films were systematically characterized using TGA and sensitive graphical Broido'd method ${ }^{[31]}$ to calculate the thermodynammical parameters of each degradation steps. The variation of dielectric properties (dielectric constant and loss factor) were measured using impedance analyzer. Morphology was examined using FE-SEM and catalytic performances for the reduction of 4-NP to 4-AP in presence of sodium borohydride was reported. 


\section{Materials and Methods}

\subsection{Materials}

Palladium chloride, poly(vinyl chloride) (Mw 233000), and trisodium citrate dihydrate were procured from Sigma Aldrich, Seoul, South Korea. All the other chemicals and solvents are of reagent grade and used without any further purification. HPLC grade water was used throughout the study.

\subsection{Synthesis of Pd-PVC and PNC-PVC composite films}

PVC films were doped with palladium (II) chloride $\left(\mathrm{PdCl}_{2}\right)$ in various concentrations, prepared at room temperature by simple solution cast method. The desired concentration of palladium chloride solutions $(2.5,5.0,7.5$ and 10.0 weight \%) were prepared by using ice cold distilled water $(800 \mu \mathrm{L})$. PVC (1g) was dissolved in $20 \mathrm{~mL}$ tetrahydrofuran (THF) at room temperature $\left(22^{\circ} \mathrm{C}\right)$, a known amount $\mathrm{PdCl}_{2}$ solutions were loaded into the PVC solutions separately. The solution was stirred for $24 \mathrm{~h}$ at room temperature and the resulting homogeneous solution was cast onto a glass plate with the aid of a casting knife. The thin films were allowed to dry at room temperature for $72 \mathrm{~h}$ and vacuum dried at $50{ }^{\circ} \mathrm{C}$ for $15 \mathrm{~h}$, the completely dried films were subsequently peeled off. The stoichiometric mass ratio of $\mathrm{PdCl}_{2}$ with respect to PVC was varied as $0.0,2.5,5.0,7.5$ and 10.0 , and the resulting thin films were designated as PVC, Pd-PVC-2.5, Pd-PVC-5.0, Pd-PVC-7.5 and Pd-PVC-10.0, respectively. The thickness of the thin films was measured at different points using peacock dial thickness gauge (Model G, Ozaki MFG. Co. Ltd., Japan) with an accuracy of $\pm 2 \mu \mathrm{m}$ and the average thickness was considered for calculation. The thickness of the membranes was found to be $345 \pm 2 \mu \mathrm{m}$.

The $\mathrm{Pd}^{+2}$ doped PVC films (Pd-PVC-2.5, Pd-PVC-5.0, Pd-PVC-7.5 and Pd-PVC-10.0) were cut in to the dimensions of $250 \mathrm{~mm} \times 250 \mathrm{~mm}$ and suspended in $50 \mathrm{~mL}$ of $1 \mathrm{mM}$ solution of trisodium citrate solution for $1 \mathrm{~h}$ with gentle stirring. The obtained composite films were washed repeatedly with distilled water, gently wiped with clothing tissue paper and vacuum dried at $50^{\circ} \mathrm{C}$ for $15 \mathrm{~h}$. The resulting Pd nanocomposite PVC films were designated as PNC-PVC-2.5, PNC-PVC-5.0, PNC-PVC-7.5 and PNC-PVC-10.0, respectively.

\subsection{Catalytic reduction of 4-nitrophenol (4-NP) to 4-aminophenol (4-AP)}

Catalytic performance of PNC-PVC-10.0 was evaluated for the model reduction reaction of 4-NP to 4-AP in a standard $10 \mathrm{~mL}$ quartz cell. Typically, $10 \mathrm{~mL}$ of aqueous 4-NP $(0.1 \mathrm{mM})$ solution was mixed with $0.05 \mathrm{~g}$ of PNC-PVC-10.0, followed by the addition of $5 \mathrm{~mL}_{\text {aqueous }} \mathrm{NaBH}_{4}$ solution $(50 \mathrm{mM})$, and the time dependent UV-vis absorption spectra was recorded by VARIANEL08043361 UV- vis spectrophotometer (Varian, USA). The conversion of 4-NP to 4 -AP was monitored every 4 min interval in a scanning range from 250 to $600 \mathrm{~nm}$ at room temperature $\left(22^{\circ} \mathrm{C}\right)$.

The percentage catalytic efficiency of the catalyst in the reduction of 4-NP into 4-AP was calculated by the following Equation (1):

$$
\text { Percentage }(\%) \text { conversion }=\frac{\mathrm{C}_{0}-\mathrm{C}_{\mathrm{t}}}{\mathrm{C}_{0}} \times 100
$$

The rate constant of the catalytic degradation of 4-NP was calculated and it falls in the pseudo first order by using the Equation (2):

$$
\ln \left[\frac{\mathrm{C}_{0}}{\mathrm{C}_{\mathrm{t}}}\right]=\mathrm{kt}
$$

where $\mathrm{C}_{\mathrm{t}}$ is the concentration of 4-NP measured at time $t, \mathrm{C}_{0}$ is the initial concentration of 4-NP measured at time zero.

\subsection{Characterization of Pd doped PVC films}

Pd doped PVC films were investigated using solid state electronic absorption spectra on a Perkin-Elmer UV-Vis spectrometer, model UV/VIS-35 (PerkinElmer, Inc., MA, USA). To understand the doping effect of $\mathrm{Pd}^{+2}$ and PdNPs content in PVC, thin films were subjected to powder X-ray diffraction study using Brucker's D-8 advanced X-ray diffractometer. The X-ray source was Ni filtered $\mathrm{Cu} \mathrm{K \alpha}$ radiation. The diffraction was scanned in the reflection mode at an angle $2 \theta$ over a range of 5 to $90^{\circ}$ at a constant speed of $8 \% \mathrm{~min}$. Similarly, the surface morphology of PNC-PVC were analyzed by using Ultra-High-Resolution Field-Emission Scanning Electron Microscope (FESEM, FEI, \& Nova NanoSEM450) instrument operating at $25 \mathrm{kV}$. Thermal stability of PVC silver nanocomposites were investigated using thermogravimetric analyzer (Q500, TA instruments, DE, USA) in the range from $25^{\circ} \mathrm{C}$ to $600^{\circ} \mathrm{C}$ in a $50 \mathrm{~mL} / \mathrm{min}$ flow of $\mathrm{N}_{2}$ gas at a heating rate of $10{ }^{\circ} \mathrm{C} / \mathrm{min}$. Pd-PVC and PNC-PVC films were subjected to the dielectric measurements; films were sandwiched between two electrodes (gold plated) and analysed by impedance analyzer, model HIOKI 3352-50 HiTESTER Version 2.3. The electrical contacts were checked to verify the ohmic connection. The measurements were carried out at room temperature in between the $50 \mathrm{~Hz}-5 \mathrm{MHz}$. The dielectric constant $\left(\varepsilon^{\prime}\right)$ was calculated using Equation (3) and dielectric loss ( $\tan \delta)$ was calculated using Equation (4).

$$
\begin{aligned}
& \varepsilon^{\prime}=\frac{\left(\mathrm{C}_{\mathrm{p}} \mathrm{d}\right)}{\left(\varepsilon_{\mathrm{o}} \mathrm{A}\right)} \\
& \tan \delta=\frac{\varepsilon^{\prime \prime}}{\varepsilon^{\prime}}
\end{aligned}
$$

where ' $d$ ' is the thickness of the polymer film and ' $A$ ' is the cross-section area, ' $\varepsilon_{\mathrm{o}}$ ' is the permittivity of the free space, ' $\varepsilon$ "' and ' $\varepsilon$ ' is the permittivity (imaginary part) and permittivity (real part) of the material respectively. All these measurements were performed under dynamic vacuum.

\section{Results and Discussions}

\subsection{Synthesis and Characterization of Pd-PVC and PNC-PVC composite films}

Pd doped PVC with different $\mathrm{PdCl}_{2}$ loading was fabricated at room temperature by adopting solution casting methodology. The desired $\mathrm{PdCl}_{2}$ was dissolved in $800 \mu \mathrm{L}$ of ice cold distilled water and added dropwise to the stirring PVC solution in tetrahydrofuran (THF) solvent. $\mathrm{Pd}^{+2}$ doped PVC films were chemically reduced using ecofriendly reducing agent, aqueous solution of trisodium citrate $(1 \mathrm{mM})$, and 
repeatedly washed with water and vaccum dried at $50{ }^{\circ} \mathrm{C}$ prior to characterization. Figure 1 displays the portrait of $\mathrm{Pd}^{+2}$ doped PVC film with 10 weight $\%$ of $\mathrm{PdCl}_{2}$ to $\mathrm{PVC}$ and its respective chemically reduced form (PNC-PVC-10.0).

Solid state UV-Vis spectra of Pd-PVC-10.0 and PNC-PVC-10.0 films were displayed in Figure 2 (a), the spectra confirms the characteristic broad continuous absorption. Pd-PVC-10.0 showed a broad peak around $400 \mathrm{~nm}$ due to the absorption of $\mathrm{Pd}^{+2}$ ions. For the reduced

(a)

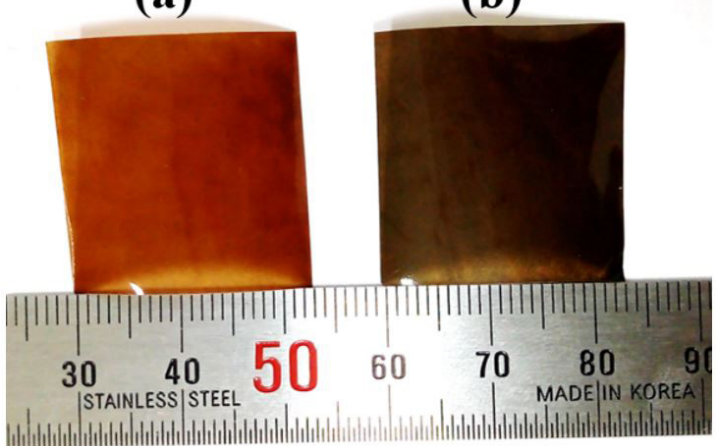

Figure 1. Snapshot of (a) Pd-PVC-10 film, (b) PNC-PVC-10.0 film.

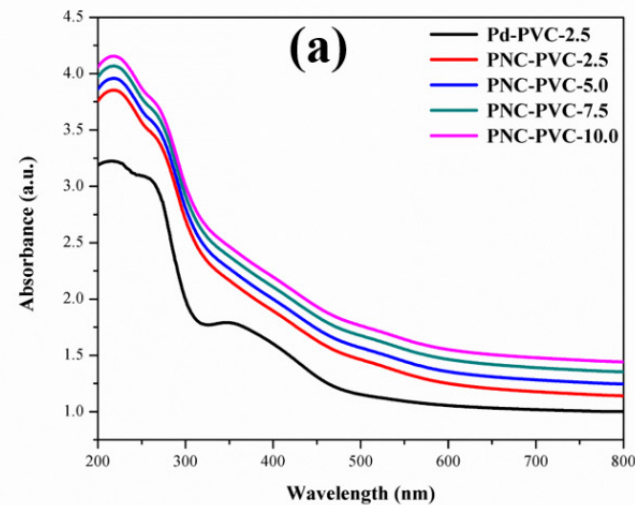

sample (PNC-PVC-10.0), the peak at $417 \mathrm{~nm}$ was absent, indicating a complete reduction of $\mathrm{Pd}^{+2}$ ions to PdNPs.

Figure 2 (b) shows the XRD pattern of PVC, Pd-PVC-10.0 and PNC-PVC-10.0. The diffraction peaks of PVC locate at $17.2^{\circ}$ and $24.5^{\circ}$, which was the amorphous characteristic pattern of PVC. The crystalline nature of the PdNPs was confirmed for PNC-PVC-10.0 by the arrival of characteristic $2 \theta$ values at $40.1^{\circ}, 46.2^{\circ}$ and $67.3^{\circ}$ corresponding to (111), (200) and (220) reflections from planes of the (face-centered cubic) fcc lattice respectively. Also, characteristic crystal planes of (311) and (222) respectively observed at $81.2^{\circ}$ and $86.1^{\circ}$.

The FE-SEM and EDX spectrum of PNC-PVC-10.0 was displayed in Figure 3 (a) and (b) respectively, The morphology shown in Figure 3 (a) from which the average size of the PdNPs is found to be less than $100 \mathrm{~nm}$ with roughly spherical morphology. Elemental composition analysis by EDX presented in Figure 3 (b), which shows strongest signal near to 2.8 to $3 \mathrm{keV}$, which is the typical absorption pattern of metallic nanocrystalline Pd surface on PVC, also strongest signals for carbon and chlorine atoms of $\mathrm{PVC}$ were obtained, indicating the presence of PdNPs in PVC matrix.

The TG plots of PVC, Pd-PVC and PNC-PVC were displayed in Figure 4, it was observed that the thermogram of PVC, Pd-PVC and PNC-PVC showed two major degradation steps with onset decomposition at $240^{\circ} \mathrm{C}$. The initial weight

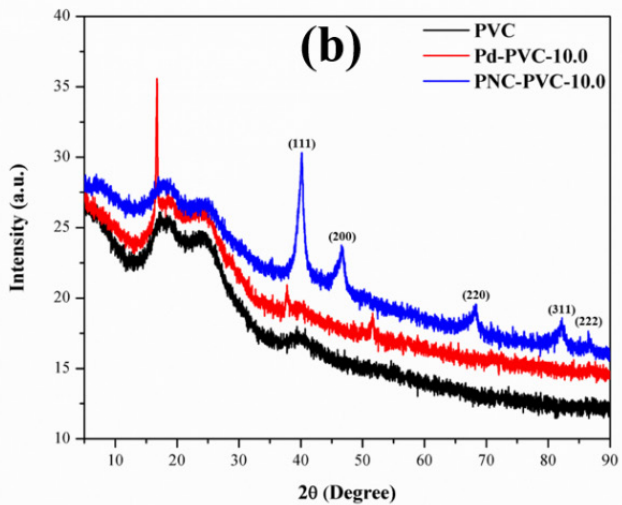

Figure 2. (a) Solid state UV-Vis spectra of Pd-PVC-2.5 and PNC-PVC films, (b) XRD pattern of PVC, Pd-PVC-10.0 and PNC-PVC-10.0 films.
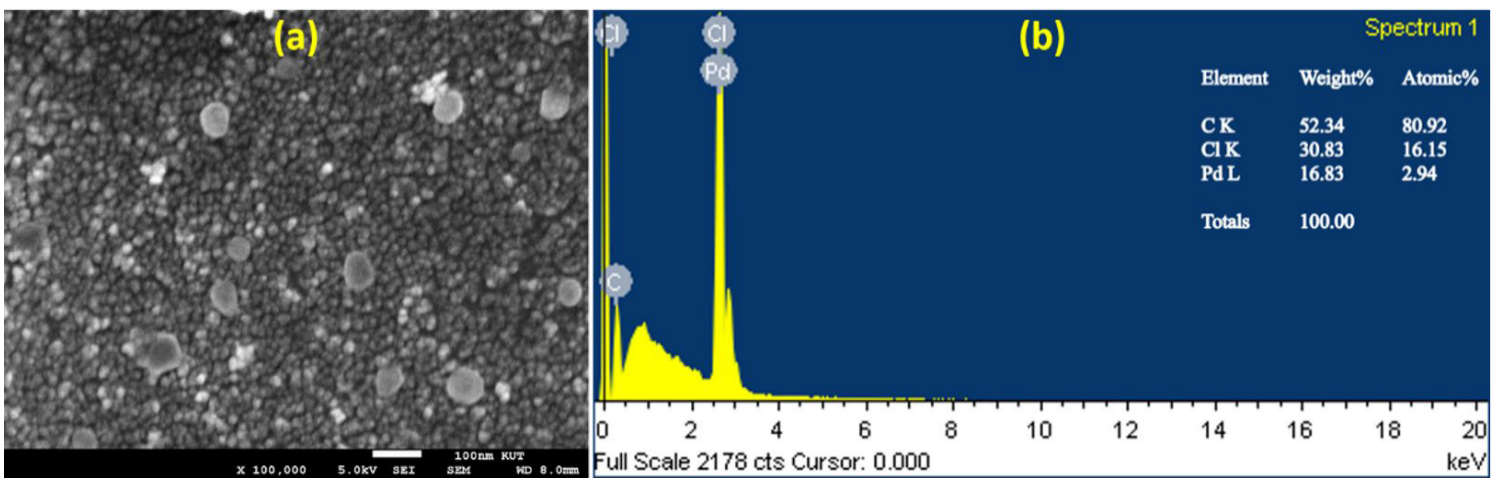

Figure 3. (a) FE-SEM micrograph of PNC-PVC-10.0. (b) EDX Spectrum of PNC-PVC-10.0. 
loss step started at around $240-340{ }^{\circ} \mathrm{C}$ was attributed to the dehydrochlorination in the PVC chains, leading to the formation of long polyene sequences in PVC chains ${ }^{[32]}$.

Second degradation step is in the range of $410-460{ }^{\circ} \mathrm{C}$ can be attributed for the degradation of main PVC chains with conjugated double bands resulted from dehydrochlorination. It is observed that PNC-PVC films are moderately stable than Pd-PVC films, this is due to the availability of large number of $\mathrm{Cl}^{-}$ions in $\mathrm{Pd}-\mathrm{PVC}$ films.

The free volume space in Pd-PVC was concealed by $\mathrm{Cl}^{-}$ions by doping $\mathrm{PdCl}_{2}$ to $\mathrm{PVC}$, which endures the faster degradation compared with PVC films. The chemical reduction of Pd-PVC films generates PdNPs on the surface of PVC, which slightly upsurges the stability of PNC-PVC compared to Pd-PVC material. Broido has developed a model and the activation energy associated with each stage of decomposition was evaluated by this method in order to find the kinetic and thermodynamic parameters for the each degradation $\operatorname{step}^{[31]}$.

Plots of $-\ln (\ln (-1 / y))$ versus $1 / T$ were developed for the decomposition segments of Pd-PVC and PNC-PVC films (Figure 5). From the plots, the activation energy $\left(E_{a}\right)$ and
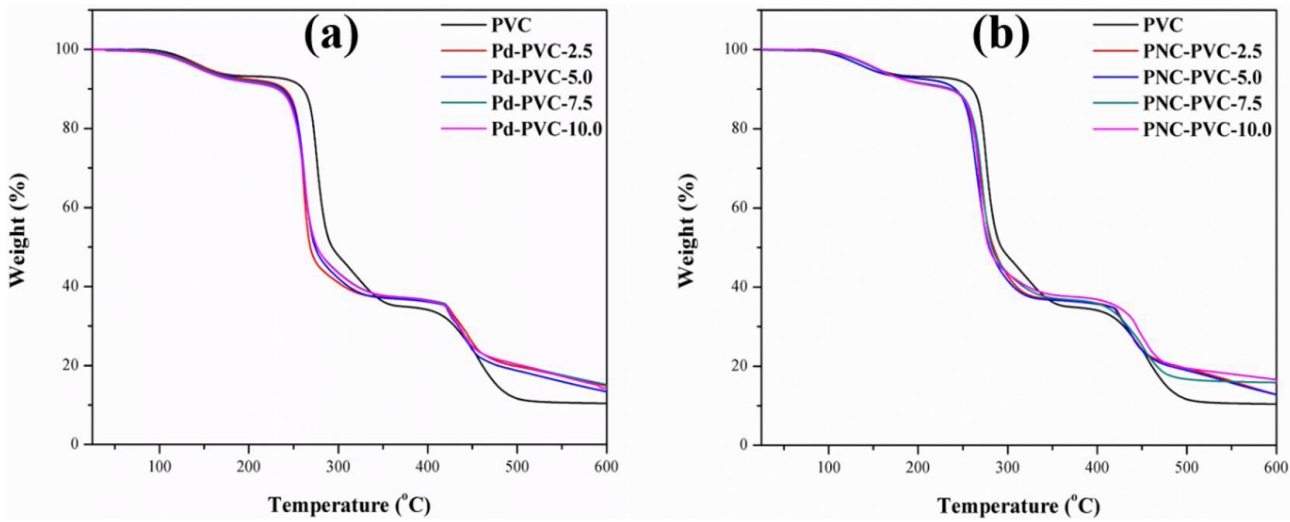

Figure 4. (a) TG plot of PVC and Pd-PVC films, (b) TG plot of PVC and PNC-PVC films at a heating rate of $10^{\circ} \mathrm{C} / \mathrm{min}$ under a nitrogen atmosphere.
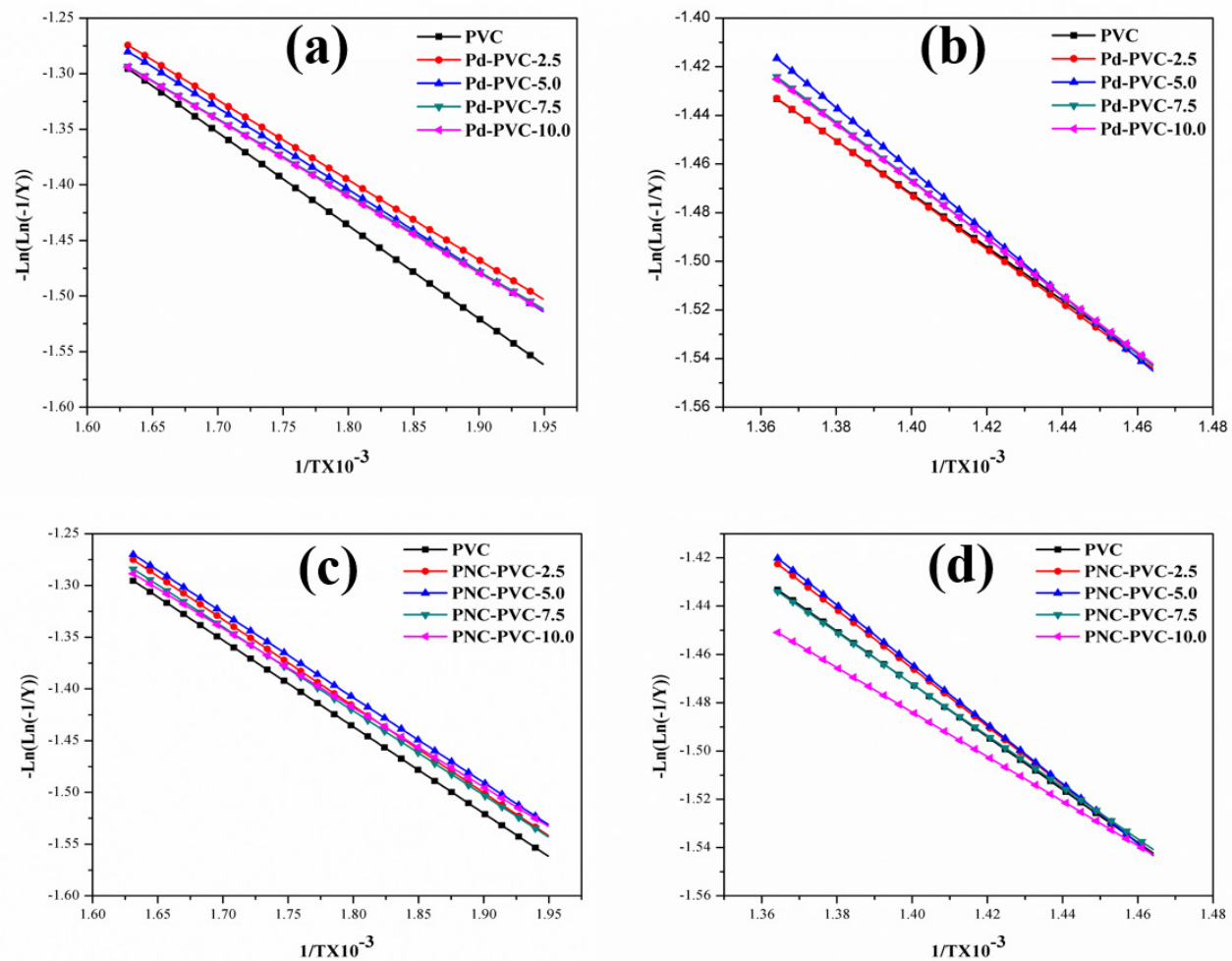

Figure 5. (a) Plots of $-\operatorname{Ln}(\ln (-1 / \mathrm{y}))$ vs $1 / \mathrm{T} \times 10^{-3}$ for the first decomposition step of Pd-PVC films in the range $240-340{ }^{\circ} \mathrm{C}$, (b) for the decomposition step of Pd-PVC films in the range $410-460{ }^{\circ} \mathrm{C}$, (c) for the first decomposition step of PNC-PVC films in the range $240-340{ }^{\circ} \mathrm{C}$, (d) for the decomposition step PNC-PVC films in the range $410-460{ }^{\circ} \mathrm{C}$. 
frequency factor $(\ln A)$ were evaluated. The enthalpy $(\Delta H)$, entropy $(\Delta S)$, and free energy $(\Delta G)$ have been calculated using standard equations and are summarized in Tables 1 , Tables 2, Tables 3 and Table 4.

From the Table 1 and 2, indicated activation energies for Pd-PVC-5.0 was higher compared to Pd-PVC-2.5, Pd-PVC-7.5 and Pd-PVC-10.0, signposting that the decomposition step is faster in case of all Pd-PVC films except Pd-PVC-5.0. This is because, higher the doping $\%$ of $\mathrm{PdCl}_{2}$, increases the content of $\mathrm{Cl}^{-}$ions in the PVC matrix, which in turn increses the rate of degradation step. However, the balance between $\mathrm{Pd}^{+2}$ and $\mathrm{Cl}^{-}$ions stabilizes the Pd-PVC-5.0 in maintaining the slow and moderate degradation rate in both the major degradation steps. The results of activation energies from Table 3 and 4 indicates that, PNC-PVC-10.0 undergoes degradation in a faster rate compared to all other PNC-PVC materials, this can be explained on the effect caused by the chemical reduction of Pd-PVC films. The chemical reduction of Pd-PVC films, results in the growth of PdNPs on the PVC surface rather than the bulk PVC material, signposting the observation of higher activation energy values in case of PNC-PVC-2.5 and PNC-PVC-5.0 compared to PNC-PVC-7.5 and PNC-PVC-10.0, this is because of the developed PdNPs on the PVC surface which stabilizes the rate of degradation step, the rate of degradation is also toggles between the presence of $\mathrm{Pd}^{+2}$ and $\mathrm{Cl}^{-}$ions inside the bullk of PVC. So, higher the content of $\mathrm{Pd}^{+2}$ and $\mathrm{Cl}^{-}$in PNC-PVC-7.5 and PNC-PVC-10.0 results in the faster degradation therein.

The variation of dielectric constant and dielectric loss as a function of $\log$ (frequency) at room temperature for Pd-PVC and PNC-PVC films were displayed in Figure 6. From the

Table 1. Kinetic and thermodynamic parameters of PVC and Pd-PVC at the decomposition range $240-340{ }^{\circ} \mathrm{C}$.

\begin{tabular}{|c|c|c|c|c|c|}
\hline \multirow{3}{*}{ Title } & $\mathbf{E}_{\mathrm{a}}$ & \multirow{3}{*}{$\ln A$} & $\Delta \mathbf{H}$ & $\Delta \mathbf{S}$ & $\Delta \mathbf{G}$ \\
\hline & $(\mathrm{kJ} / \mathrm{mol})$ & & \multirow{2}{*}{$(\mathrm{kJ} / \mathrm{mol})$} & \multirow{2}{*}{$(\mathbf{k J} / \mathbf{K})$} & \multirow{2}{*}{$(\mathrm{kJ} / \mathrm{mol})$} \\
\hline & $\times 10^{-3}$ & & & & \\
\hline PVC & 16.020 & -6.557 & -4.665 & -160.350 & 90.292 \\
\hline Pd-PVC-2.5 & 13.753 & -6.823 & -4.668 & -159.207 & 89.648 \\
\hline Pd-PVC-5.0 & 14.077 & -6.789 & -4.667 & -159.534 & 89.832 \\
\hline Pd-PVC-7.5 & 13.126 & -6.932 & -4.668 & -159.798 & 89.981 \\
\hline Pd-PVC-10.0 & 13.179 & -6.926 & -4.668 & -159.821 & 89.994 \\
\hline
\end{tabular}

Table 2. Kinetic and thermodynamic parameters of PVC and Pd-PVC at the decomposition range $410-460{ }^{\circ} \mathrm{C}$.

\begin{tabular}{|c|c|c|c|c|c|}
\hline \multirow{3}{*}{ Title } & $\mathbf{E}_{\mathrm{a}}$ & \multirow{3}{*}{$\ln A$} & $\Delta \mathbf{H}$ & $\Delta \mathbf{S}$ & $\Delta \mathbf{G}$ \\
\hline & (kJ/mol) & & \multirow{2}{*}{$(\mathrm{kJ} / \mathrm{mol})$} & \multirow{2}{*}{$(\mathrm{kJ} / \mathrm{K})$} & \multirow{2}{*}{$(\mathrm{kJ} / \mathrm{mol})$} \\
\hline & $\times 10^{-3}$ & & & & \\
\hline $\mathrm{PVC}$ & 20.927 & -5.696 & -5.865 & -161.688 & 114.475 \\
\hline Pd-PVC-2.5 & 20.927 & -5.695 & -5.865 & -161.663 & 114.457 \\
\hline Pd-PVC-5.0 & 24.642 & -5.208 & -5.861 & -161.486 & 114.332 \\
\hline Pd-PVC-7.5 & 22.789 & -5.444 & -5.863 & -161.493 & 114.336 \\
\hline Pd-PVC-10.0 & 22.470 & -5.486 & -5.864 & -161.508 & 114.347 \\
\hline
\end{tabular}

Table 3. Kinetic and thermodynamic parameters of PVC and PNC-PVC at the decomposition range $240-340{ }^{\circ} \mathrm{C}$.

\begin{tabular}{|c|c|c|c|c|c|}
\hline \multirow{3}{*}{ Title } & $\mathbf{E}_{\mathrm{a}}$ & \multirow{3}{*}{$\ln A$} & $\Delta \mathbf{H}$ & $\Delta \mathbf{S}$ & $\Delta \mathbf{G}$ \\
\hline & (kJ/mol) & & \multirow{2}{*}{$(\mathrm{kJ} / \mathrm{mol})$} & \multirow{2}{*}{$(\mathbf{k J} / \mathbf{K})$} & \multirow{2}{*}{$(\mathrm{kJ} / \mathrm{mol})$} \\
\hline & $\times 10^{-3}$ & & & & \\
\hline PVC & 16.013 & -6.558 & -4.665 & -160.358 & 90.283 \\
\hline PNC-PVC-2.5 & 16.019 & -6.540 & -4.665 & -159.863 & 90.004 \\
\hline PNC-PVC-5.0 & 15.702 & -6.571 & -4.665 & -159.560 & 89.833 \\
\hline PNC-PVC-7.5 & 15.562 & -6.599 & -4.665 & -159.863 & 89.989 \\
\hline PNC-PVC-10.0 & 14.689 & -6.712 & -4.666 & -159.736 & 89.932 \\
\hline
\end{tabular}

Table 4. Kinetic and thermodynamic parameters of PVC and PNC-PVC at the decomposition range $410-460{ }^{\circ} \mathrm{C}$.

\begin{tabular}{|c|c|c|c|c|c|}
\hline \multirow{3}{*}{ Title } & $E_{a}$ & \multirow{3}{*}{$\ln A$} & $\Delta \mathbf{H}$ & $\Delta \mathbf{S}$ & $\Delta \mathbf{G}$ \\
\hline & $(\mathrm{kJ} / \mathrm{mol})$ & & \multirow{2}{*}{$(\mathrm{kJ} / \mathrm{mol})$} & \multirow{2}{*}{$(\mathbf{k J} / \mathbf{K})$} & \multirow{2}{*}{$(\mathrm{kJ} / \mathrm{mol})$} \\
\hline & $\times 10^{-3}$ & & & & \\
\hline $\mathrm{PVC}$ & 20.927 & -5.696 & -5.865 & -161.688 & 114.475 \\
\hline PNC-PVC-2.5 & 23.093 & -5.403 & -5.863 & -161.450 & 114.306 \\
\hline PNC-PVC-5.0 & 23.609 & -5.337 & -5.863 & -161.448 & 114.305 \\
\hline PNC-PVC-7.5 & 20.485 & -5.753 & -5.866 & -161.656 & 114.452 \\
\hline PNC-PVC- 10.0 & 17.643 & -6.158 & -5.866 & -161.984 & 114.685 \\
\hline
\end{tabular}



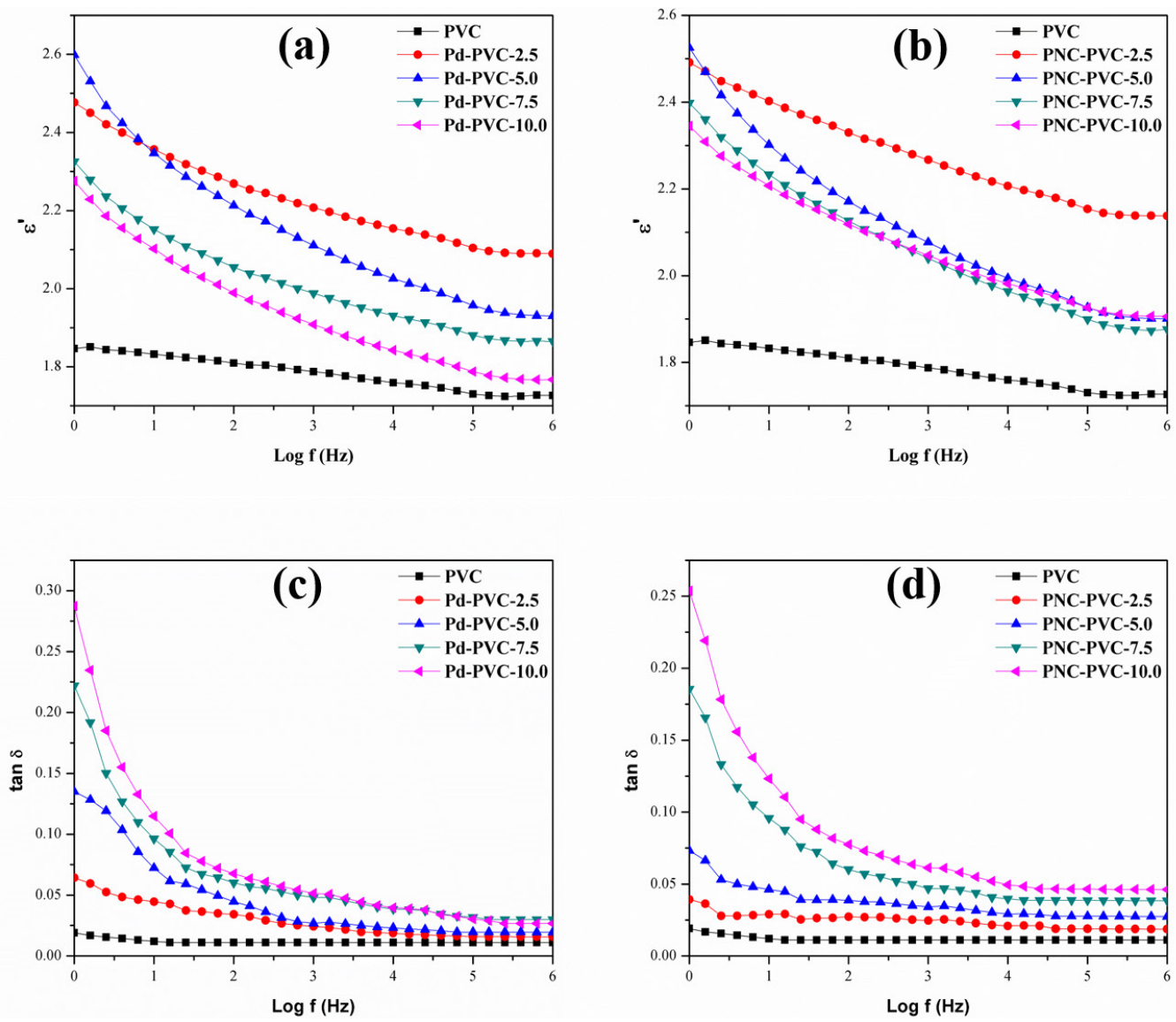

Figure 6. Room temperature dielectric constant variation of (a) Pd-PVC, (b) PNC-PVC films, dielectric loss variation of (c) Pd-PVC (d) PNC-PVC films with log frequency.

Figure 6 (a) plot it is evident that, there is a marginal decrease in the dielectric constant over the measured frequency range with respect to increase in the $\mathrm{Pd}^{+2}$ loading was observed. The dielectric constant increased with $\mathrm{Pd}^{+2}$ loading and reached an optimum value of 2.6 at $5 \%$ loading. The rate of decrease is larger at higher frequency region indicating quasi-DC (QDC) behavior ${ }^{[33]}$. As the frequency increases, pace maintenance and the orientation of dipolar groups with alternating field seems to be difficult, resulting in a continuously decreasing dielectric constant with increase of $\mathrm{Pd}^{+2}$ doping to PVC.

From Figure 6 (b), we can notify further decrease of dielectric constant for PNC-PVC films, this is because the $\mathrm{Pd}^{+2}$ ions are chemically reduced to $\mathrm{Pd}^{0}$ on the surface of PVC, resulting not much contribution to the dielectric constant. The decrease in the dielectric constant can also be plained by the restriction of polarization mechanisms in the bulk of the material. Also, the density of dopant ions $\left(\mathrm{Pd}^{+2}, \mathrm{Cl}^{-}\right.$and $\left.\mathrm{Pd}^{0}\right)$ in $\mathrm{PVC}$ matrix ${ }^{[34]}$.

From Figure 6 (c) and (d), it was noted that loss factor of Pd-PVC and PNC-PVC films decreases with increase in frequency. There is a marginal increase in the dielectric loss with doping of $\mathrm{Pd}^{+2}$. Since, the presence of charge carriers in the PVC matrix increases by the sequential doping of $\mathrm{Pd}^{+2}$, increases the dissipation factor was observed. For $2.5 \%$ doping of $\mathrm{Pd}^{+2}$, the dissipation factor was below 0.5 at lower frequencies. A slight PVC chain entanglements and less hinderence for the movement of charge carriers were observed, resulting in minor increase in the loss factor on $\mathrm{Pd}^{+2}$ doping. In case of PNC-PVC, due to unavailability of $\mathrm{Pd}^{+2}$ ions at the PVC surface due to chemical reduction, PdNPs might hinder the movement of charge in the material causing slight decrease in $\tan \delta$ component. Overall the loss factor is within the range of 0.25 to 0.3 for all the composite films at $1 \mathrm{~Hz}$.

\subsection{Catalytic activity}

The model reduction reaction of 4-NP to 4-AP in the presence of aqueous $\mathrm{NaBH}_{4}$ was studied in presence of catalyst PNC-PVC-10.0. Before starting the reduction reaction, the UV-Vis absorbance spectrum of 4-NP solution with $\mathrm{NaBH}_{4}$ solution was recorded. The UV-Vis spectrum shows the $\lambda_{\max }$ of $400 \mathrm{~nm}$ for 4-NP, in presence of catalyst PNC-PVC-10.0, arrival of another peak at $\lambda_{\text {max }}$ of $300 \mathrm{~nm}$ was observed due to the formation of 4-AP. The complete conversion of 4-NP to 4-AP was observed after $20 \mathrm{~min}$. The reduction of 4-NP to 4-AP in the presence of $\mathrm{NaBH}_{4}$ as a model reaction was depicted in Figure 7 (a).

The apparent rate constant $\left(k_{\text {app }}\right)$ and correlation constants $\left(\mathrm{R}^{2}\right)$ for PNC-PVC-10.0 were calculated using linear plots of 

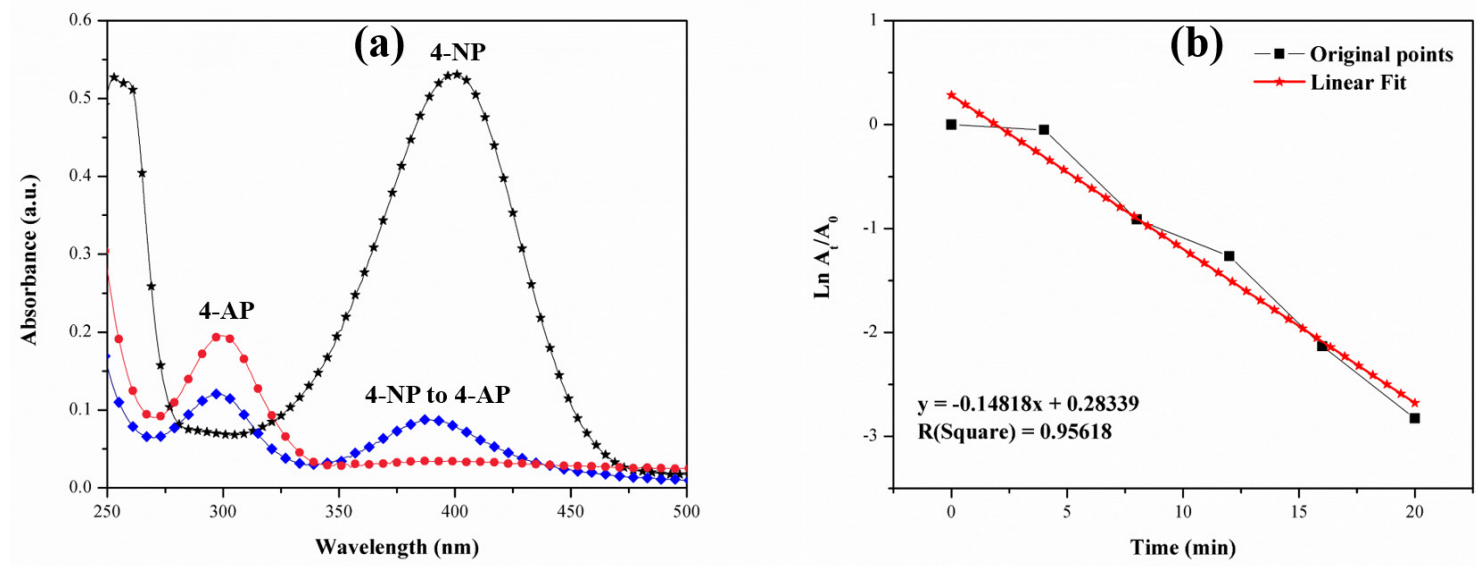

Figure 7. (a) Time dependant UV-Vis spectra representing the catalytic reduction of 4-NP into 4-AP, (b) linear plot of $-\ln \left(\mathrm{A}_{\mathrm{t}} / \mathrm{A}_{\mathrm{o}}\right)$ versus reduction time (t) for PNC-PVC-10.0 catalyst.

Table 5. Catalytic reduction of 4-NP to 4-AP using PNC-PVC-10.0 catalyst.

\begin{tabular}{cc}
\hline \multirow{2}{*}{ Time $(\boldsymbol{m i n})$} & \% Conversion of \\
\cline { 2 - 2 } & 4-NP to 4-AP \\
\hline 0 & 0 \\
4 & 4.407 \\
8 & 18.327 \\
12 & 27.443 \\
16 & 88.133 \\
20 & 94.273 \\
\hline
\end{tabular}

$-\ln \left(\mathrm{A}_{\mathrm{t}} / \mathrm{A}_{\mathrm{o}}\right)$ versus reduction time $(\mathrm{t})$ was shown in Figure 7 (b). The percentage conversion of 4-NP to 4-AP with respect to reduction time $(\mathrm{t})$ by PNC-PVC-10.0 catalyst was reported in Table 5, the apparent rate constant $\left(k_{\text {app }}\right)$ calculated for the reaction was $2.371 \times 10^{-3} \mathrm{sec}^{-1}$.

The catalytic reduction was carried out in a closed $50 \mathrm{~mL}$ glass vial. Typically, $100 \mathrm{mg}$ of finely chopped (1 mm x $10 \mathrm{~mm}$ ) PNC-PVC-10.0 films were inserted into the mixture of $10 \mathrm{~mL}$ of $0.1 \mathrm{mM}$ aqueous 4-NP and $5 \mathrm{~mL}$ of $50 \mathrm{mM}$ aqueous $\mathrm{NaBH}_{4}$ solution, the rate of reaction drastically changes, the intense yellow color the reaction mixture (aqueous 4-NP and $\mathrm{NaBH}_{4}$ solution) was diminished to colorless in $20 \mathrm{~min}$ (Table 5). The catalytic reduction reaction was monitored by time dependant UV-visible spectrophotometer. The mechanism involved in the reduction groups to convert it into amino $\left(-\mathrm{NH}_{2}\right)$ groups. The electron transfer from donor $\left(\mathrm{BH}_{4}^{-}\right.$ions) to acceptor (4-NP ions) was facilitated by PNC-PVC-10.0 (heterogeneous solid catalyst).

PNC-PVC-10.0 shows considerable catalytic performances with exhibited apparent rate constant $\left(k_{\text {app }}\right) 2.371 \times 10^{-3} \mathrm{sec}^{-1}$ which was significantly higher than $1.5 \times 10^{-3} \mathrm{sec}^{-1}$ reported for polystyrene based thermosensitive microgel encapsulated PdNPs reported by Mei et al. ${ }^{[35]}$.

Recently, Zhang et al. ${ }^{[36]}$ in 2017 , reported the catalytic activities of bimetallic Pt@Pd alloy cubic nanocomposites with reported $k_{A P P} 2.0 \times 10^{-3} \mathrm{sec}^{-1}$. The $k_{A P P}$ value reported by Adekoya et al. ${ }^{[37]}$ for polyol based nanobimettalic $\mathrm{Ag} / \mathrm{Pd}$ Polyvinyl pyrollidone composites was $1.9 \times 10^{-3} \mathrm{sec}^{-1}$ at $90{ }^{\circ} \mathrm{C}$. Esumi et al. ${ }^{[38]}$ reported palladium nanocomposites of poly(amidoamine)s dendrimer $k_{A P P}$ value of $17.9 \times 10^{-4} \mathrm{sec}^{-1}$. The $k_{A P P}$ value reported here for PNC-PVC-10.0 was considerably close to the value $2.4 \times 10^{-3} \mathrm{sec}^{-1}$ for 17 weight $\%$ PdNPs deposited on citrate-functionalized graphene oxide ${ }^{[39]}$.

\section{Conclusions}

A simple solution casting technique was adopted to fabricate palladium doped PVC composites from 2.5 to $10.0 \%$ (stochiometric). The thermal stability of all the materials were studied using TGA, using sensitive graphical Broido's method to evaluate thermodynamical parameters at each stage of thermal degradation steps. The PdNPs in the PVC matrix was confirmed by UV-Vis, XRD, EDX. The PdNPs in PNC-PVC-10.0 were studied using FE-SEM and it was found that PdNPs were uniformly distributed with size less than $100 \mathrm{~nm}$. EDX elemental composition of PNC-PVC at any place of the film clears the uniform distribution of PdNPs. It was found that dielectric constant and loss factor for all the composites were marginally increased with Pd doping to PVC films. Since, Pd based self healing coatings are very familiar as anti-corrosion interfaces in automotive and aerospace engineering applications, proper tuning of noble metals and Pd coatings can be a useful candidate for electronic applications ${ }^{[40]}$. The article also highlights the catalytic performances of PNC-PVC-10.0 for a model reduction reaction of 4-NP using aqueous $\mathrm{NaBH}_{4}$ solution. The calculated apparent rate constant $\left(k_{\text {app }}\right)$ was $2.371 \times 10^{-3} \mathrm{sec}^{-1}$ at room temperature, the correlation coefficient $\left(\mathrm{R}^{2}\right)$ was found to be 0.956 for PNC-PVC-10.0. Our results demonstrates that these PNC-PVC films are ideal materials as heterogeneous catalysts and prove their potential applications as nanocatalysts in industrial catalysis.

\section{Acknowledgements}

This work was supported by the Technology Innovation Program (10077367, Development of a film-type transparent /stretchable 3D touch sensor /haptic actuator combined module and advanced UI/UX) funded by the Ministry of Trade, Industry \& Energy (MOTIE, Korea). This work was also supported by Priority Research Centers 
Program through the National Research Foundation of Korea (NRF) funded by the Ministry of Education (NRF-2018R1A6A1A03025526). Thanks for Cooperative Equipment Center at KoreaTech for assistance with UV-Vis, TGA, XRD and FESEM analysis.

\section{References}

1. Sápi, Z., Butler, R., \& Rhead, A. (2019). Filler materials in composite out-of-plane joints - A review. Composite Structures, 207, 787-800. http://dx.doi.org/10.1016/j.compstruct.2018.09.102.

2. Xue, Y., Gao, C., Liang, L., Wang, X., \& Chen, G. (2018). Nanostructure controlled construction of high-performance thermoelectric materials of polymers and their composites. Journal of Materials Chemistry. A, Materials for Energy and Sustainability, 6(45), 22381-22390. http://dx.doi.org/10.1039/ C8TA09656B.

3. Sebati, W., \& Ray, S. S. (2018). Advances in nanostructured metal-encapsulated porous organic-polymer composites for catalyzed organic chemical synthesis. Catalysts, 8(11), 74. http://dx.doi.org/10.3390/catal8110492.

4. Zhang, X., Chen, Y., \& Hu, J. (2018). Recent advances in the development of aerospace materials. Progress in Aerospace Sciences, 97, 22-34. http://dx.doi.org/10.1016/j. paerosci.2018.01.001.

5. Shintake, J., Cacucciolo, V., Floreano, D., \& Shea, H. (2018). Soft robotic grippers. Advanced Materials, 30(29), e1707035. http://dx.doi.org/10.1002/adma.201707035. PMid:29736928.

6. Li, H., Yang, P., Pageni, P., \& Tang, C. B. (2017). Recent advances in metal-containing polymer hydrogels. Macromolecular Rapid Communications, 38(14), 1700109. http://dx.doi.org/10.1002/ marc.201700109. PMid:28547817.

7. Alarco, P. J., Abu-Lebdeh, Y., Abouimrane, A., \& Armand, M. (2004). The plastic-crystalline phase of succinonitrile as a universal matrix for solid-state ionic conductors. Nature Materials, 3(7), 476-481. http://dx.doi.org/10.1038/nmat1158. PMid: 15195084.

8. Hötzel, G., \& Weppner, W. (1986). Application of fast ionic conductors in solid state galvanic cells for gas sensors. Solid State Ionics, 18-19(2), 1223-1227. http://dx.doi.org/10.1016/01672738(86)90338-3.

9. Kumar, R. V. (1997). Application of rare earth containing solid state ionic conductors in electrolytes. Journal of Alloys and Compounds, 250(1-2), 501-509. http://dx.doi.org/10.1016/ S0925-8388(96)02643-6.

10. Shen, Y., Xia, S., Yao, P., Hugh Gong, R., Liu, Q., \& Deng, B. (2017). Structure regulation and properties of melt-electrospinning composite filter materials. Fibers and Polymers, 18(8), 15681579. http://dx.doi.org/10.1007/s12221-017-7172-1.

11. Saxena, S., \& Saxena, U. (2016). Development of bimetal oxide doped multifunctional polymer nanocomposite for water treatment. International Nano Letters, 6(4), 223-234. http:// dx.doi.org/10.1007/s40089-016-0188-5.

12. Ploss, B., \& Krause, M. (2007). Doped polymers as matrix materials for ferroelectric composites. Ferroelectrics, 358(1), 77-84. http://dx.doi.org/10.1080/00150190701534155.

13. Yaacob, M. M., Kamaruddin, N., Mazlan, N. A., Noramat, N. F., Alsaedi, M. A., \& Aman, A. (2014). Dielectric properties of polyvinyl chloride with wollastonite filler for the application of high-voltage outdoor insulation material. Arabian Journal for Science and Engineering, 39(5), 3999-4012. http://dx.doi. org/10.1007/s13369-014-0996-8.

14. Orrit-Prat, J., Mujal-Rosas, R., Rahhali, A., Marin-Genesca, M., Colom-Fajula, X., \& Belana-Punseti, J. (2010). Dielectric and mechanical characterization of PVC composites with ground tire rubber. Journal of Composite Materials, 45(11), 1233-1243. http://dx.doi.org/10.1177/0021998310380289.
15. Singh, A. P., \& Singh, Y. P. (2016). Dielectric behavior of $\mathrm{CaCu}_{3} \mathrm{Ti}_{4} \mathrm{O}_{12}$ : poly vinyl chloride ceramic polymer composites at different temperature and frequencies. Modern Electronic Materials, 2(4), 121-126. http://dx.doi.org/10.1016/j. moem.2017.01.001.

16. Li, R., Zhou, J., Liu, H., \& Pei, J. (2017). Effect of polymer matrix on the structure and electric properties of piezoelectric lead zirconatetitanate/polymer composites. Materials (Basel), 10(8), 945. http://dx.doi.org/10.3390/ma10080945. PMid:28805730.

17. Abdel-Baset, T., Elzayat, M., \& Mahrous, S. (2016). Characterization and optical and dielectric properties of polyvinyl chloride/silica nanocomposites films. International Journal of Polymer Science, 11(2), 169-181. http://dx.doi. org/10.1155/2016/1707018.

18. Taha, T. A., \& Azab, A. A. (2019). Thermal, optical, and dielectric investigations of $\mathrm{PVC} / \mathrm{La}_{0.95} \mathrm{Bi}_{0.05} \mathrm{FeO}_{3}$ nanocomposites. Journal of Molecular Structure, 1178, 39-44. http://dx.doi. org/10.1016/j.molstruc.2018.10.018.

19. Taha, T. A., Ismail, Z., \& Elhawary, M. M. (2018). Structural, optical and thermal characterization of $\mathrm{PVC} / \mathrm{SnO}_{2}$ nanocomposites. Applied Physics. A, Materials Science \& Processing, 124(4), 307. http://dx.doi.org/10.1007/s00339-018-1731-1.

20. Taha, T. A. (2017). Optical and thermogravimetric analysis of $\mathrm{Pb}_{3} \mathrm{O}_{4} / \mathrm{PVC}$ nanocomposites. Journal of Materials Science Materials in Electronics, 28(16), 12108-12114. http://dx.doi. org/10.1007/s10854-017-7024-1.

21. Taha, T. A., \& Saleh, A. (2018). Dynamic mechanical and optical characterization of PVC/fGO polymer nanocomposites. Applied Physics. A, Materials Science \& Processing, 124(9), 600. http://dx.doi.org/10.1007/s00339-018-2026-2.

22. Taha, T. A. (2018). Optical properties of $\mathrm{PVC} / \mathrm{Al}_{2} \mathrm{O}_{3}$ nanocomposites films. Polymer Bulletin, 76(2), 903-918. http://dx.doi.org/10.1007/s00289-018-2417-8.

23. Taha, T. A., Hendawy, N., El-Rabaie, S., Esmat, A., \& El-Mansy, M. K. (2018). Effect of NiO NPs doping on the structure and optical properties of PVC polymer films. Polymer Bulletin, l(1), 1-11. http://dx.doi.org/10.1007/s00289-018-2633-2.

24. Al-Hartomy, O. A., Al-Salamy, F., Al-Ghamdi, A. A., AbdelFatah, M., Dishovsky, N., \& El-Tantawy, F. (2011). Influence of graphite nanosheets on the structure and properties of PVCbased nanocomposites. Journal of Applied Polymer Science, 120(6), 3628-3634. http://dx.doi.org/10.1002/app.33547.

25. Broza, G., Piszczek, K., Schulte, K., \& Sterzynski, T. (2007). Nanocomposites of poly (vinyl chloride) with carbon nanotubes (CNT). Composites Science and Technology, 67(5), 890-894. http://dx.doi.org/10.1016/j.compscitech.2006.01.033.

26. Al-Ghamdi, A. A., El-Tantawy, F., Abdel Aal, N., ElMossalamy, E. H., \& Mahmoud, W. E. (2009). Stability of new electrostatic discharge protection and electromagnetic wave shielding effectiveness from poly (vinyl chloride)/graphite/ nickel nanoconducting composites. Polymer Degradation \& Stability, 94(6), 980-986. http://dx.doi.org/10.1016/j. polymdegradstab.2009.02.012.

27. Ebnalwaled, A. A., \& Thabet, A. (2016). Controlling the optical constants of PVC nanocomposite films for optoelectronic applications. Synthetic Metals, 220, 374-383. http://dx.doi. org/10.1016/j.synthmet.2016.07.006.

28. Baghbamidi, S. E., Hassankhani, A., Sanchooli, E., \& Sadeghzadeh, S. M. (2018). The reduction of 4-nitrophenol and 2-nitroaniline by palladium catalyst based on a KCC-1/ IL in aqueous solution. Applied Organometallic Chemistry, 32(4), e4251. http://dx.doi.org/10.1002/aoc.4251.

29. Kästner, C., \& Thünemann, A. F. (2016). Catalytic reduction of 4-Nitrophenol using silver nanoparticles with adjustable activity. Langmuir, 32(29), 7383-7391. http://dx.doi.org/10.1021/acs. langmuir.6b01477. PMid:27380382. 
30. Rambabu, D., Pradeep, C. P., Pooja, A., \& Dhir, A. (2015). Self-assembled material of palladium nanoparticles and a thiacalix[4]arene $\mathrm{Cd}(\mathrm{II})$ complex as an efficient catalyst for nitro-phenol reduction. New Journal of Chemistry, 39(10), 8130-8135. http://dx.doi.org/10.1039/C5NJ01304F.

31. Broido, A. (1969). A simple, sensitive graphical method of treating thermogravimetric analysis data. Journal of Polymer Science. Part A-2, Polymer Physics, 7(10), 1761-1773. http:// dx.doi.org/10.1002/pol.1969.160071012.

32. Van Der Ven, S., \& De Wit, W. F. (1969). Thermal degradation of poly(vinyl chloride): the accelerating effect of hydrogen chloride. Die Angewandte Makromolekulare Chemie, 8(1), 143-152. http://dx.doi.org/10.1002/apmc.1969.050080110.

33. Dissado, L. A., \& Hill, R. M. (1984). Anomalous low-frequency dispersion. Near direct current conductivity in disordered low-dimensional materials. Journal of the Chemical Society, Faraday Transactions 2 Molecular and Chemical Physics, 80(3), 291-319. http://dx.doi.org/10.1039/f29848000291.

34. Aspnes, D. E., Studna, A. A., \& Kinsbron, E. (1984). Dielectric properties of heavily doped crystalline and amorphous silicon from 1.5 to $6.0 \mathrm{eV}$. Physical Review. B, 29(2), 768-779. http:// dx.doi.org/10.1103/PhysRevB.29.768.

35. Mei, Y., Lu, Y., Polzer, F., Ballauff, M., \& Drechsler, M. (2007). Catalytic activity of palladium nanoparticles encapsulated in spherical polyelectrolyte brushes and core-shell microgels. Chemistry of Materials, 19(5), 1062-1069. http://dx.doi. org $/ 10.1021 / \mathrm{cm} 062554 \mathrm{~s}$.
36. Zhang, J., Gan, W., Fu, X., \& Hao, H. (2017). A microwave assisted one-pot route synthesis of bimetallic PtPd alloy cubic nanocomposites and their catalytic reduction for 4-nitrophenol. Materials Research Express, 4(10), 105022. http://dx.doi. org/10.1088/2053-1591/aa8f70.

37. Adekoya, J. A., Dare, E. O., Mesubi, M. A., Nejo, A. A., Swart, H. C., \& Revaprasadu, N. (2014). Synthesis of polyol based $\mathrm{Ag} / \mathrm{Pd}$ nanocomposites for applications in catalysis. Results in Physics, 4, 12-19. http://dx.doi.org/10.1016/j.rinp.2014.02.002.

38. Esumi, K., Isono, R., \& Yoshimura, T. (2004). Preparation of PAMAM- and PPI-Metal (Silver, Platinum, and Palladium) nanocomposites and their catalytic activities for reduction of 4-Nitrophenol. Langmuir, 20(1), 237-243. http://dx.doi. org/10.1021/la035440t. PMid:15745027.

39. Su, B., Jia, Y., Zhang, S., Chen, X., \& Oyama, M. (2014). Synthesis of palladium nanoparticles on citrate-functionalized graphene oxide with high catalytic activity for 4-Nitrophenol reduction. Chemistry Letters, 43(6), 919-921. http://dx.doi org/10.1246/cl.140105.

40. Cohen, U., Walton, K. R., \& Sard, R. (1984). Development of silver-palladium alloy plating for electrical contact applications. Journal of the Electrochemical Society, 131(11), 2489-2495. http://dx.doi.org/10.1149/1.2115330.

Received: Dec. 18, 2018

Revised: Feb. 03, 2019

Accepted: Feb. 18, 2019 